\title{
Mediação de Conflitos: impactos de uma intervenção pedagógica uma escola pública na Amazónia Ocidental do Brasil
}

\author{
Franciane de Oliveira Pinho ${ }^{1}$, Rafael Fonseca de Castro ${ }^{1}$ e \\ Elisabete Pinto da Costa ${ }^{2}$
}

\author{
1 Universidade Federal de Rondônia (UNIR), Brasil | francianepinho@gmail.com; \\ castro@unir.br | https://orcid.org/0000-0002-3836-8981; https://orcid.org/0000-0001- \\ 5897-851 \\ ${ }^{2}$ Universidade Lusófona do Porto, Centro de Estudos Interdisciplinares em Educação e \\ Desenvolvimento (CieED), Portugal | elisabete.pinto.costa@ulp.com | \\ https://orcid.org/0000-0002-6255-4135
}

\begin{abstract}
Resumo: Este trabalho apresenta resultados da implementação da mediação de conflitos, enquanto proposta de intervenção pedagógica para lidar com a indisciplina numa escola pública da cidade de Porto Velho, no Estado de Rondônia, na Amazónia Ocidental do Brasil. O estudo justificou-se pela manifestação crescente da indisciplina, com prejúzo dos processos de ensino e desenvolvimento cognitivo e social dos estudantes. Acresce não haver pesquisas stricto sensu sobre a mediação aplicada à educação na região norte do Brasil, tampouco estudos que promovam o diálogo entre a mediação escolar com a Teoria Histórico-Cultural da Atividade. A intervenção teve a duração de quatro meses, no período de agosto a novembro de 2019 , tendo participado da pesquisa dezoito estudantes de uma turma do $7^{\circ}$ ano, nove professores e quatro profissionais da equipa de gestão da escola. Tratou-se de uma pesquisa de abordagem qualitativa, de tipo intervenção pedagógica, cujas etapas consistiram na análise situacional, sensibilização, formação, institucionalização e avaliação. Foram realizados oito encontros com estudantes, cinco com docentes e seis com a equipa gestora, totalizando dezanove encontros. A avaliação da intervenção foi realizada através de observação, questionário e entrevista. Os dados recolhidos foram organizados e analisados em três categorias. i) convivência na escola; ii) mediação de conflitos na escola; iii) efeitos da mediação de conflitos). Entre os principais resultados, constata-se que os estudantes manifestaram que a mediação proporcionou mudanças positivas na convivência escolar; os docentes afirmaram a necessidade de adequação da prática pedagógica à sala de aula, com o intuito de diminuir as situações de indisciplina, e a equipa gestora reconheceu a relevância da mediação como estratégia de prevenção da indisciplina, percebendo a mudança de postura nos estudantes e também nos docentes.
\end{abstract}

Palavras-chave: Mediação de Conflitos; Teoria Histórico-Cultural da Atividade; Intervenção Pedagógica.

Conflict Mediation: Impacts of a Pedagogical Intervention in a Public School in the Western Amazon of Brazil

Abstract: This article presents results of the implementation of conflict mediation, as a proposal for pedagogical intervention to deal with indiscipline in a public school in Porto Velho city, the State of Rondônia, in the Western Amazon of Brazil. The study was justified by the growing manifestation of indiscipline, to the detriment of the processes of teaching and students 'cognitive and social development. Moreover, there are no stricto sensu research on mediation applied to education in the Northern Region of Brazil, nor studies that promote dialogue between school mediation and the Cultural-Historical Theory activity. The intervention lasted four months, from August to November 2019, with eighteen students from a 7th grade class, nine teachers, and four professionals from the school's management team participating in the research. This was a research of qualitative approach, of pedagogical intervention, whose stages consisted of situational analysis, sensitization, training, institutionalization, and evaluation. Eight meetings were held with students, five with teachers, and six with the management team, totalling nineteen meetings. The evaluation of the intervention was carried out through observation, questionnaire and interview. The data collected was organized and analyzed into three categories: i) coexistence at school; ii) conflict mediation at school; iii) effects of conflict mediation). Among the main results, it was found that students expressed that mediation provided positive changes in school coexistence; teachers affirmed the need to adapt the pedagogical practice to the classroom in order to decrease indiscipline situations and the management team recognized the relevance of mediation as a strategy to face indiscipline, noticing the change of posture in students and also in teachers.

Keywords: Conflict Mediation; Cultural-Historical Theory of Activity; Pedagogical Intervention. 


\section{Introdução}

O presente estudo resulta de uma pesquisa de mestrado, cujo objetivo consistiu em analisar e compreender uma intervenção pedagógica realizada segundo a metodologia da mediação de conflitos, com vista à redução da indisciplina, numa escola pública de Porto Velho, capital do Estado de Rondónia, na Amazónia Ocidental do Brasil. Neste artigo apresentam-se resultados da avaliação da intervenção pedagógica implementada.

Entre os autores que no Brasil estudam a indisciplina escolar destacam-se Aquino (1996), Rêgo (1996), Garcia (1999) e Vasconcellos (2009), que a concebem como uma condicionante que prejudica tanto as atividades de ensino como o desenvolvimento intelectual dos estudantes. Em concordância com estes autores, entende-se por indisciplina a manifestação da incongruência entre os critérios e expectativas assumidos pela escola e os comportamentos e atitudes de socialização entre estudantes e também entre estes e os docentes.

Destaca-se a importância da escola na vida do homem, enquanto sujeito histórico e social. Na concepção da Teoria Histórico-Cultural da Atividade (CHAT'1), Daniez e Smolka (2014) advogam que ao estudar o desenvolvimento humano busca-se caracterizar os aspectos tipicamente humanos do comportamento e elaborar hipóteses sobre como essas características se formam ao longo da história humana e de como se desenvolvem durante a vida de um indivíduo. Esta perspectiva teórica fundamentou a proposta de implementação da mediação de conflitos, que também se apresentou de tipo intervenção pedagógica, de acordo com os pressupostos de Damiani et al. (2013).

Considera-se a articulação entre mediação de conflitos e intervenção pedagógica fundamental, tanto para a gestão da (in)disciplina escolar, como para a produção de conhecimento científico acerca desse tipo de estratégia, bem como para a divulgação de uma boa prática pela qual se pretende lidar com problemáticas sociais que se manifestam nas escolas, como é o caso da escola pública em estudo.

\section{Fundamentação teórica}

\subsection{Mediação de Conflitos}

A mediação de conflitos consiste num método e num processo dialógico, não adversarial, de gestão e resolução de conflitos, por meio do qual os sujeitos podem chegar a um acordo de ganho mútuo, sendo, para o efeito, indispensável identificar os verdadeiros interesses e as reais possibilidades, de forma que se compreendam reciprocamente (Costa, 2019). Neste estudo, as concepções acerca da mediação estão articuladas com o conflito (latente ou manifesto) em ambiente escolar.

A mediação é então um procedimento pacífico por meio do qual um terceiro, alheio à situação conflito, atua para encorajar e facilitar a resolução do conflito pelas partes de forma construtiva (Sales, 2003; 2007). Entende-se também a mediação como um método, mais ou menos estruturado, que pode ocorrer de modo formal ou informal, e no qual o mediador auxilia as partes envolvidas num conflito a trabalhar o entendimento e 0 reconhecimento, em busca de uma solução mutuamente satisfatória.

Em virtude das potencialidades educativas e capacitadoras que the estão associadas, segundo Costa, Torrego e Martins (2016), a mediação ultrapassa os limites da resolução de conflitos, porquanto também fomenta o desenvolvimento de competências na gestão de relações interpessoais e de convivência, proporcionando oportunidades de aprendizagem e de crescimento dos individuos.

${ }^{1}$ Segundo o Center for Activity Theory and Developmental Work Research, da Universidade de Helsinquia (http://www.edu.helsinki.fi/activity/pages/chatanddwr/chat/), esta denominação é usada para designar o conjunto de ideias desenvolvidas pelo grupo de psicólogos russos revolucionários, que iniciaram sua atuação nos anos 1920 e 1930, sob a liderança de Lev Vygotsky (DAMIANI et al., 2013). 
A mediação de conflitos pode apresentar-se à escola como uma metodologia para operacionalizar a cultura da convivência, que se substitua à cultura da adversidade (Soares, 2017). Também para esta autora, a mediação vai além de técnicas ou ferramentas para resolução de conflitos, pois propõe, na sua essência, uma nova cultura de gestão relacional e social.

No seguimento desta argumentação, apresentam-se finalidades multifacetadas à mediação, tais como: criadora, renovadora, preventiva e curativa (Six, 2003). Soares (2017) menciona que a mediação em contexto escolar também agrega finalidades diversas, tais como: 1) educação para a convivência; 2) prevenção da incivilidade, da agressividade e da violência; 3) prevenção e solução de conflitos, na lógica dos "3R": resolução, reconciliação e reparação; 4) ação transformadora, resultante da reconciliação e da revalorização entre os sujeitos e; 5) como modelo integrado de gestão da convivência, que aproveita os conflitos, estimula as habilidades e cria culturas sociais pacíficas.

Por sua vez, Ortega e Del Rey (2002) apontam uma relevante preocupação quanto à ameaça de "se converter a convivência num cenário de transtornos do comportamento e na tendência a introduzir, na instituição escolar, um modelo clínico que não é necessário, nem conveniente" (p. 144). Nessa perspectiva, a mediação seguiria uma vertente contrária à sua finalidade essencial, na medida em que o seu objetivo principal é promover mecanismos educativos e capacitadores para que os sujeitos encontrem, por si mesmos e em conjunto, por meio de uma comunicação não violenta, soluções para as questões dilemáticas que enfrentam nos seus contextos relacionais, sem que, por isso, se converta num mecanismo para lidar com alguma espécie de patologia instaurada.

Já para Vygotski (1982), a mediação (seja entre docente, estudante, tutor, livro ...) constitui a oportunidade para se estabelecer condições e meios de promoção da reflexividade entre as partes em interação. Dessa mediação tende a resultar uma nova realidade, que derive do empoderamento do indivíduo.

A amplitude da mediação está também presente nos projetos de mediação de conflitos adotados em contexto escolar. Estes evoluíram de programas de mediação de pares para projetos de amplo espectro, com foco não apenas na intervenção junto aos alunos, mas também incorporando a restante comunidade educacional e a escola (Pinto da Costa, 2019). Em síntese, o propósito destes projetos de intervenção pode estar associado tanto a um modelo centrado na pessoa, em que gerir a convivência implica a adoção de um modelo de regulação da disciplina e dos conflitos, que mantém uma dimensão formativa, ou a um modelo centrado na organização e cultura escolar.

\subsection{Pesquisa do Tipo Intervenção Pedagógica}

A intervenção pedagógica neste estudo teve na base conceitos de Damiani et al. (2013), que advogam a produção de conhecimento a partir das interferências sobre problemas educacionais concretos e específicos. A intervenção pedagógica entendida nesta perspectiva envolve: i) planeamento; ii) implementação de medidas em função das mudanças e/ou de inovações com a intenção de produzir avanços/melhorias em processos de gestão, ensino e aprendizagem entre os sujeitos que neles se encontram envolvidos; e ainda iii) avaliação dos efeitos da intervenção.

A pesquisa do tipo intervenção pedagógica distingue-se basicamente da pesquisa básica, por que a primeira suscita no investigador a possibilidade de condução de uma prática. É importante ressaltar que na pesquisa interventiva, tal como sustentava Vygotski (1995) perante o estudo dos fenómenos numa perspectiva histórica, as mudanças ocorrem no decorrer do tempo. Segundo o autor, "a investigação histórica da conduta não é algo que complementa ou ajuda o estudo teórico, senão que constitui o seu fundamento" (idem, p. 65). Segundo esta abordagem argumentativa, a pesquisa do tipo intervenção pedagógica pode alinhar-se pela perspectiva histórica de investigação em Educação. 
Assim, o principal propósito da articulação entre a pesquisa de tipo intervenção pedagógica pela mediação com a perspectiva histórico-cultural consistiu em estabelecer na escola esta metodologia alicerçadora de uma cultura relacional e social de sã convivência, suplantando a cultura dominante impregnada de antivalores ao humanismo (como: competição, humilhação, discriminação).

No centro da mudança socioeducativa, que não se pretende pontual, mas antes sustentável, estão os indivíduos que se envolvem na construção da cultura de convivência cidadã. Seja o estudante, enquanto ator da comunidade escolar, que é educado e capacitado para exercer protagonismo, seja a escola, enquanto sujeito cultural, que desempenha a função de educar de forma integral.

A intervenção pedagógica realizada no âmbito deste estudo baseou-se nos pressupostos da mediação de conflitos e teve como referência Torrego (2003), Costa (2019) e Cunha e Monteiro (2019). Em síntese, para que a mediação de conflitos ocorra na escola é necessário realizar um diagnóstico dos problemas de convivência na comunidade educativa e das necessidades socioeducativas para desenhar a intervenção; programar a planificação da intervenção; realizar as atividades pedagógicas de mediaçao, através de sessões formativas; avaliar as atividades e devolver os resultados à escola para análise das potencialidades da mediação e desse modo a potenciar o envolvimento de todos os atores educativos nas atividades de mediação.

\section{Metodologia}

\subsection{Objetivo Geral e Questões de Pesquisa}

O objetivo geral deste estudo consistiu em analisar e compreender os efeitos de uma intervenção pedagógica com recurso à metodologia da mediação de conflitos, na gestão da indisciplina, numa escola pública de Porto Velho, capital do Estado de Rondónia no Brasil. Decorrente deste objetivo geral definiu-se a seguinte questão de pesquisa: quais os efeitos da implementação da mediação de conflitos numa escola pública de Porto Velho? E, consequentemente, definiram-se as seguintes subquestões de pesquisa: i) na perspetiva dos estudantes, quais os efeitos da implementação da mediação de conflitos na escola?; ii) na perspetiva dos docentes, quais os efeitos da implementação da mediação de conflitos na escola?; iii) i) na perspetiva dos elementos da equipa gestora, quais os efeitos da implementação da mediação de conflitos na escola; iv) qual o contributo da CHAT para a mediação de conflitos na escola?.

\subsection{Participantes e Contexto}

O estudo foi realizado na Amazónia Ocidental do Brasil, na capital do Estado de Rondónia, em Porto Velho, numa escola pública de ensino fundamental, localizada na região periférica norte.

Participaram da pesquisa dezoito estudantes de uma turma do $7^{\circ}$ ano do ensino fundamental, nove professores e quatro profissionais da equipa gestora da escola. A instituição foi indicada pela coordenadoria regional de ensino de Porto Velho (CRE/PVH), em função da necessidade de intervir na indisciplina registada. A turma intervencionada foi proposta pela equipa gestora da escola.

Entre os estudantes, dois terços eram do sexo masculino e os restantes do sexo feminino. Três estudantes (dois meninos e uma menina) estavam em situação de retenção. Os docentes participantes apresentaram diferentes tempos de serviço na escola: um estava a lecionar há três meses; cinco docentes referiram entre sete e dez anos de serviço a escola e os restante três lecionavam há mais de quinze anos. Entre os elementos da equipa gestora, uma técnica educacional referiu que trabalhava na escola há cinco meses, enquanto as demais já trabalhavam há mais de vinte e um anos, desempenhando funções como docentes e funções na gestão educacional. 
A intervenção pedagógica que constituiu este estudo teve a duração de quatro meses, entre agosto e novembro de 2019. Tratou de uma investigação integrada no grupo de investigação HISTCULT da Universidade Federal de Rondônia (UNIR) e que dispõe do Projeto de Pesquisa "Intervenções Pedagógicas em Rondônia: inovação educacional e produção de conhecimento em Educação". A pesquisa foi realizado por uma investigadora, com orientação de um professor Universidade Federal de Rondônia do Brasil e, mais recentemente, com o apoio e uma docente da Universidade Lusófona do Porto de Portugal.

\subsection{Método, Instrumentos e Procedimento}

Em coerência com o objetivo geral do estudo, a investigação foi de cariz qualitativo, que, simultaneamente, orientou a pesquisa da intervenção pedagógica implementada. Conforme Damiani et al. (2013), neste tipo de pesquisa o investigador planeia e intervém numa determinada situação educacional com a intenção de aprimorar processos pedagógicos nos mais diversos contextos e níveis dos sistemas educacionais e, posteriormente, avaliar os efeitos produzidos.

Bauer e Gaskell (2002) apresentam dois critérios específicos para a pesquisa qualitativa, classificando-os como "equivalentes funcionais" à pesquisa quantitativa, a saber: relevância e confiabilidade. Por exemplo, no que se refere à confiabilidade da pesquisa foram utilizados antes, durante e após a intervenção, métodos e instrumentos para a recolha de dados, tais como: observação participante e entrevista semiestruturada (organizadas tendo em conta os contributos de Bauer \& Gaskell, 2002; Minayo, 2001, Gil, 2017) e ainda questionário (numa perspectiva interpretativa, sem recurso à manipulação de variáveis) (Morgado, 2012).

Todo o processo interventivo-pedagógico foi elaborado conforme preconizam Damiani et al. (2013) e as cinco etapas pincipais de intervenção foram definidas tendo por referência Costa (2019), a saber: 1 - análise situacional; 2 - sensibilização; 3 - formação; 4 implementação; 5 - avaliação. Estas etapas estão descritas no quadro seguinte:

Quadro 1. Sistematização das etapas de intervenção

\begin{tabular}{|c|c|c|c|c|}
\hline Etapa & $\begin{array}{l}\text { Método/ } \\
\text { Instrumento }\end{array}$ & Temáticas & Participantes & Período \\
\hline \multirow{4}{*}{$\begin{array}{l}\text { Análise } \\
\text { situacional }\end{array}$} & $\begin{array}{l}\text { Observação (encontro } \\
\text { temático) }\end{array}$ & & \multirow{3}{*}{$\begin{array}{l}\text { Estudantes, } \\
\text { docentes e } \\
\text { equipa } \\
\text { gestora }\end{array}$} & \multirow{3}{*}{ Agosto/19 } \\
\hline & $\begin{array}{l}\text { Entrevista (pré } \\
\text { encontro temático) }\end{array}$ & $\begin{array}{l}\text { Clima de convivência na } \\
\text { escola }\end{array}$ & & \\
\hline & $\begin{array}{l}\text { Questionário (pré- } \\
\text { intervenção) }\end{array}$ & & & \\
\hline & $\begin{array}{l}\text { Observação } \\
\text { (encontros temáticos) }\end{array}$ & $\begin{array}{l}\text { Conflito na concepção dos } \\
\text { estudantes }\end{array}$ & Estudantes & $\begin{array}{l}\text { Setembro e } \\
\text { outubro/19 }\end{array}$ \\
\hline \multirow[t]{2}{*}{ Sensibilização } & $\begin{array}{l}\text { Entrevista (pós } \\
\text { encontros temáticos) }\end{array}$ & $\begin{array}{l}\text { Conflito na concepção dos } \\
\text { docentes }\end{array}$ & $\begin{array}{l}\text { Docentes e } \\
\text { equipa } \\
\text { gestora }\end{array}$ & Setembro/19 \\
\hline & $\begin{array}{l}\text { Observação (Oficina } \\
\text { temática) }\end{array}$ & $\begin{array}{l}\text { Conflito e indisciplina Vs } \\
\text { mediação de conflitos } \\
\text { Ser mediador }\end{array}$ & Estudantes & \multirow{3}{*}{$\begin{array}{c}\text { Outubro e } \\
\text { novembro/19 }\end{array}$} \\
\hline \multirow[t]{2}{*}{ Formação } & $\begin{array}{l}\text { Entrevista (pós-oficina } \\
\text { temática) }\end{array}$ & $\begin{array}{l}\text { Convivência escolar } \\
\text { Indisciplina escolar }\end{array}$ & \multirow{2}{*}{$\begin{array}{l}\text { Docentes e } \\
\text { equipa } \\
\text { gestora }\end{array}$} & \\
\hline & $\begin{array}{l}\text { Questionário } \quad \text { (pós- } \\
\text { intervenção) }\end{array}$ & & & \\
\hline $\begin{array}{l}\text { Institucionali- } \\
\text { zação }\end{array}$ & $\begin{array}{l}\text { Observação } \\
\text { (encontros temáticos) }\end{array}$ & $\begin{array}{l}\text { Institucionalização } \\
\text { mediação na escola }\end{array}$ & $\begin{array}{l}\text { Equipa } \\
\text { gestora }\end{array}$ & Novembro/19 \\
\hline Avaliação & $\begin{array}{l}\text { Questionário } \\
\text { (avaliação final) }\end{array}$ & Avaliação do projeto & $\begin{array}{l}\text { Estudantes, } \\
\text { docentes e } \\
\text { equipa } \\
\text { pedagógica }\end{array}$ & Novembro/19 \\
\hline
\end{tabular}


Em síntese, para a recolha de dados foram realizados oito encontros com estudantes, cinco encontros com docentes e seis com a equipa gestora, num total de dezenove encontros, abrangendo as fases de diagnóstico, planeamento, implementação e avaliação da intervenção (Damiani et al., 2013).

A pesquisa foi aprovada pelo Comité de Ética da UNIR (CAAE - 21119019.5.0000.5300) e, no cumprimento das questões éticas, os participantes foram identificados com nomes de líderes de notória atuação em causas pela paz.

Para a análise de dados foi utlizada a técnica de análise de conteúdo, nos termos da qual, e após a leitura flutuante dos dados obtidos, procedeu-se à codificação desses dados segundo três principais categorias previamente definidas (i) convivência na escola; ii) mediação de conflitos na escola; iii) efeitos da mediação de conflitos) e que permitiram então a análise dos resultados alcançados e possibilitaram a construção do conhecimento acerca dos efeitos da implementação da mediação de conflitos em contexto escolar segundo a concepção da CHAT.

\section{Análise e Discussão dos Resultados}

Sobre a intervenção pedagógica pela mediação de conflitos analisaram-se opiniões, percepções e significações de estudantes, docentes e equipa gestora que participaram no estudo. No quadro seguinte destacam-se três relatos mais relevantes acerca dos efeitos dessa intervenção numa perspectiva de pré e pós-intervenção.

Quadro 2. Análise comparativa pré e pós-intervenção

\begin{tabular}{|c|c|}
\hline \multicolumn{2}{|c|}{ Estudante: Malala Yousafzai } \\
\hline Pré-intervenção & Pós-intervenção \\
\hline $\begin{array}{l}\text { Observação da pesquisadora: agressiva com as } \\
\text { palavras, brincadeiras depreciativas, agitada. } \\
\text { Estudante Malala Yousafzai: } \\
\text { "Que bobagem esse negócio de mediação de } \\
\text { conflitos". (entrevista) }\end{array}$ & $\begin{array}{l}\text { Observação da pesquisadora: desenvolveu } \\
\text { diversos aspectos positivos, como por exempo: } \\
\text { liderança positiva em sala de aula, controle das } \\
\text { palavras depreciativas e conduta diferenciada com } \\
\text { os colegas em sala de aula. Contribuiu muito nas } \\
\text { etapas interventivas do projeto. } \\
\text { Estudante Malala Yousafzai: } \\
\text { "No início, pensei que isso não ia dar em nada, mas, } \\
\text { cada vez ficava melhor, muitas atividades onde a } \\
\text { gente podia falar sobre o que a gente achava e em } \\
\text { ajudar o outro a ser melhor. A nossa sala, nenhum } \\
\text { professor queria vir pra cá, mas estamos } \\
\text { melhorando" (questionário) }\end{array}$ \\
\hline
\end{tabular}

\begin{tabular}{|c|c|}
\hline \multicolumn{2}{|c|}{ Docente: Wangari Maathai } \\
\hline Pré-intervenção & Pós-intervenção \\
\hline $\begin{array}{l}\text { "Chegam muitos projetos aqui na escola, } \\
\text { infelizmente, são pessoas que não conhecem a } \\
\text { realidade da escola, quero ver ficar aqui por vários } \\
\text { meses com os alunos" (entrevista) }\end{array}$ & $\begin{array}{l}\text { "Esse projeto de mediação de conflitos foi bem } \\
\text { diferente dos demais. Passei a ver os alunos de uma } \\
\text { forma diferente, também, acho que passei a ter mais } \\
\text { paciência em escutar e tentar ajudar, não só ficar } \\
\text { preocupada com o conteúdo. Seria um projeto que } \\
\text { daria muito certo na escola" (questionário) }\end{array}$ \\
\hline \multicolumn{2}{|c|}{ Elemento da equipa gestora } \\
\hline Pré-intervenção & Pós-intervenção \\
\hline $\begin{array}{l}\text { "Acredito muito na discussão e no debate em sala de } \\
\text { aula com os alunos, principalmente, sobre essa } \\
\text { temática de mediação de conflitos, pois todos os } \\
\text { dias nos deparamos com conflitos de todas as } \\
\text { ordens aqui na escola. Estou disponível sempre que } \\
\text { precisar. Seja bem-vinda!" (entrevista) }\end{array}$ & $\begin{array}{l}\text { "Saiba que, com certeza, o projeto sobre mediação } \\
\text { de conflitos na escola, foi muito importante no } \\
\text { processo de construção da escola como um todo, } \\
\text { pois todos ganhamos com isso: os alunos, } \\
\text { empolgados e participando, os professores com um } \\
\text { olhar mais cautelosos e eu na gestão com um } \\
\text { desafio de não deixar esse grupo desanimar. Na } \\
\text { realidade, todos ganhamos com o projeto. Queria } \\
\text { muito que o projeto fosse ampliado para as demais } \\
\text { turmas, sei que seria muito bom para todos da } \\
\text { escola" (questionário) }\end{array}$ \\
\hline
\end{tabular}


Dos relatos apresentados supra foram explícitas as manifestações positivas em relação à mediação de conflitos, permitindo observar que no início os participantes não acreditavam na ação propulsora da intervenção. Entretanto, com as ações desenvolvidas em sala de aula, passaram a perceber o benefício proporcionado pelas aprendizagens adquiridas. Apresenta-se outro conjunto de relatos proferidos por uma estudante, uma professora e um elemento da equipa gestora:

Malala Yousafzai: "maravilhoso, agora, na sala, conseguimos conversar antes de brigar ou falar mal do outro. Conseguimos ver que a intervenção na sala de aula teve efeito com agente. Hoje, conseguimos conversar e eles nos escutam, existe diálogo" (questionário)

Ellen Johnson: "foi muito salutar as formações e a intervenção, uma vez que agregou conhecimentos e ensinamentos para trabalharmos em sala de aula a indisciplina e os conflitos com os alunos. Esse projeto deveria ser constante na escola" (questionário)

Elemento da equipa gestora: "os professores tomaram posse das discussões e materiais que foram trabalhados e isso ficou claro em algumas situações que ocorreram, na qual os professores utilizaram a metodologia da mediação de conflitos, chegavam dizendo que tinha tido uma situação em sala, mas que haviam reunido os alunos em sala e argumentaram com todos. Então, está surtindo o efeito que esperamos a utilização devida do diálogo em sala" (questionário)

Os resultados alcançados, cujos dados foram apresentados sumariamento acima, indicaram uma avaliação positiva da intervenção pedagógica, corroborando a tendência afirmada pelos autores utilizados como referência para este estudo (Torrego, 2003; Costa, 2019; Cunha e Monteiro, 2019), especialmente considerando a mudança entre o antes e o após da intervenção. Com efeito, constatou-se que os sujeitos passaram a desenvolver atitudes conscientes que são preventivas de indisciplina e proativas de uma sã convivência. Segundo Vygotski (1931/1995), como explica Castro (2019), no momento em que se passa a ter consciência de determinado processo psicológico é possível controlálo. No ambiente educacional, os sujeitos intervencionados passaram a ter controlo de processos e elementos necessários para a condução das situações de conflito, diminuindo as ocorrências de indisciplina no contexto escolar.

Apesar dos resultados positivos alcançados, através dos quais se pretende suportar processos (históricos) de convivência saudável, a intervenção pedagógica deparou-se com constrangimentos. Grande parte dos pedagogos e membros da equipa gestora participaram pouco das atividades formativas ou não participaram de forma efetiva das formações com docentes e estudantes. Se por um lado, constatou-se a necessidade de aumentar o número de participantes e de alongar a duração da intervençao para alcançar uma maior relevância dos resultados, por outro lado, verificou-se que o apoio da equipa gestora pode fazer a diferença. Como refere Costa (2019), considera-se que o apoio da equipa gestora é fundamental para sustentabilidade da intervenção pedagógica, de maneira a influir na cultura relacional dos indivíduos, mas também na cultura organizacional da escola.

\section{Conclusões}

O processo de investigação teve como objetivo analisar os efeitos de uma intervenção pedagógica pela mediação de conflitos, que permitisse enfrentar a indisciplina, numa escola pública de Porto Velho, do Estado de Rondónia, na Amazónia Ocidental do Brasil. Essa intervenção partiu do pressuposto de que a mediação de conflitos pode constituir uma estratégia construtiva para instituir uma cultura de sã convivência.

Para elencar as ideias finais do estudo considera-se essencial retomar a questão de pesquisa: quais os efeitos da implantação da estratégia de mediação de conflitos numa escola pública de Porto Velho? 
Para responder tal questionamento destacam-se os resultados alcançados por grupo de participantes e para os quais foi fundamental a abordagem de pesquisa qualitativa e a aplicação de vários instrumentos de recolha de dados, porquanto contribuiu para (re)conhecer as significações dos sujeitos em relação à intervenção pedagógica realizada e assim comparar com outros estudos pelos quais se guiou esta investigação (que também privilegiaram a pesquisa qualitativa). Torna-se fulcral construir conhecimento científico, com confiabilidade, patente no recurso à triangulação de dados recolhidos por vários instrumentos e junto de vários participantes, o que pode permitir que demais escolas possam adoptar estratégias semelhantes.

Entre os estudantes observou-se: (i) maior atenção quanto ao uso da linguagem violenta e adoção de comportamento não ofensivo; (ii) tentativa de solucionar os seus conflitos antes de terceirizá-los; (iii) melhoria do ambiente da sala de aula, refletindo-se na diminuição da hostilidade. Quanto aos docentes constatou-se: (i) compreensão da metodologia da mediação de conflitos e dos seus benefícios para o contexto educacional; (ii) percepção da necessidade de ações para a melhoria do clima escolar e, consequentemente, para as práticas pedagógicas; (iii) consciência da necessidade de implementar atividades extracurriculares para melhorar as interações entre estudantes, pais e escola; (iv) abertura para o diálogo com os estudantes; (v) tomada de consciência das ações na gestão dos conflitos no quotidiano. Quanto ao elemento da equipa gestora verificou-se: (i) compreensão da metodologia da mediação de conflitos e dos seus benefícios no contexto educacional; (ii) consciência da necessidade de realizar ações formativas com docentes nas temáticas da intervenção; (iii) tomada de consciência das suas ações na gestão dos conflitos no quotidiano.

Com base nos resultados apresentados, considerou-se que a intervenção pedagógica produziu efeitos importantes no contexto educacional, em particular naqueles que se envolveram nas atividades realizadas. Com efeito, emergiu uma atitude reflexiva por parte de estudantes, docentes e do elemento da equipa gestora em relação às questões relacionais, aos conflitos e sobre como estes devem ser trabalhados pedagogicamente.

Determinantes histórico-culturais da vida escolar, como conflitualidade, indisciplina e violência, integram a rotina educacional. Jares (2002) afirma que tal cenário pode mudar, especialmente quando a escola faz uso das potencialidades da sua missão educadora e socializadora. Esta conceção do autor aponta, por isso, para a mudança dos determinantes históricos-culturais do contexto socioeducativo escolar. Nesta perspetiva apresentou-se o projeto de intervenção pedagógica à escola com a intenção de viabilizar uma metodologia que atendesse às necessidades socio-educativas identificadas nesse contexto histórico e cultural. Nesse projeto adoptou-se a metodologia da mediação de conflitos e a intervenção fundamentou-se nos pressupostos da CHAT.

Apesar das aproximações teórico-práticas e metodológicas entre mediação de conflitos e CHAT, apresentamos a necessidade de maior aprofundamento. No entanto, os participantes da pesquisa tomaram consciência (Vygotski, 1925/1991; Prestes, 2010; Castro, 2019) de atitudes e ações relacionais que carecem de empoderamento social. Corrobora-se a ideia de Davydov, Slobodchikov e Tsukerman (2003, pp. 5,6), para quem a formação deve ocorrer no sentido de propiciar aos sujeitos tornarem-se "sujeitos individuais de reflexão", sujeitos aprendizes com "capacidade para viver em um mundo em constante mudança".

Contudo, considera-se necessário maior aprofundamento dos pressupostos da CHAT e da relação com a teoria da Mediação, assim como de um maior diálogo desses pressupostos com os dados da investigação. Em consequência, defende-se a continuidade de mais investigações qualitativas nesta linha de pesquisa. 


\section{Referências}

Aquino, J. G. (Org.) (1996). Indisciplina na escola: alternativas teóricas e práticas. São Paulo: Summus Editorial.

Bauer, M. W., \& Gaskell, G. (2002). Pesquisa Qualitativa com Texto, Imagem e Som: um manual prático. Petrópolis: Vozes Press.

Castro, R. F. de. (2019). Consciência em L. S. Vygotsky: vislumbrando potencialidades de aplicação em práticas pedagógicas. In: ANPEd, 2019, Rio de Janeiro. Anais do... Rio de Janeiro: 39 ${ }^{\text {a }}$ Reunião Nacional da ANPEd, Rio de Janeiro, Brasil.

Costa, E.P.; Torrego, J. \& Martins, A. (2016). Gabinetes de Mediação de Conflitos: estrutura de pacificação, dinâmica e resultados. In A. M. C. Silva; M. L. Carvalho \& L. R. Oliveira (EDS.). Sustentabilidade da mediação social: processos e práticas. Braga: CECS - Centro de Estudos de Comunicação e Sociedade. Universidade do Minho, pp. 107-118.

Costa, E. P. (2019). Mediação de conflitos em contexto escolar: da teoria à prática. Lisboa: Edições Lusófonas.

Cunha, P., \& Monteiro, A. P. (2019). Gestão de conflitos na escola. Lisboa: Edições Pactor.

Damiani, M. F., Rochefort, R. S., Castro, R. F. de., Dariz, M. R., \& Pinheiro, S. S. (2013). Discutindo pesquisas do tipo intervenção pedagógica. Pelotas - Brasil, Cadernos de Educação, n. 45, 57-67.

Daniez, D., \& Smolka, A. L. B (2014). O conceito de compreensão no diálogo de Vygotsky com Adler: desenvolvimento humano, educação e deficiência. Educ. Pesquisa, v. 40, n. 4, 10931108.

Davydov, V.V., Slobodchikov, V. I., \& Tsukerman, G. A. (2003). O aluno das séries iniciais do ensino fundamental como sujeito da atividade de estudo. Journal of Russian and East European Psychology, 41, 4.

Garcia, J. (1999). Indisciplina na escola: uma reflexão sobre a dimensão preventiva. Curitiba-Brasil, Revista Paranaense de Desenvolvimento, 95, 101-108.

Gil, A. C. (2017). Como elaborar projetos de pesquisa. São Paulo: Editora Atlas.

Jares, X. R. (2002). Educação e conflito - Guia de educação para a convivência. Porto: Edições ASA.

Minayo, M. C. S (2001). Pesquisa social. Teoria, método e criatividade. Petrópolis: Vozes.

Morgado, J. (2012). O estudo de caso na investigação e educação. Santo Tirso: Da facto Editores.

Ortega, R., \& Del Rey, R. (2002). Construir la convivencia. Barcelona: Edebé.

Prestes, Z. R. (2010). Quando não é quase a mesma coisa: análises de traduções de Lev Semionovitch Vigotski no Brasil: Repercussões no campo educacional. [Tese de doutorado Programa de Pós-Graduação em Educação, Faculdade de Educação, Universidade de Brasília].

Rêgo, T. C. (1996). A indisciplina e o processo educativo: uma análise na perspectiva vygotskiana. In J. G. Aquino (Org.). Indisciplina na escola: alternativas, teóricas e práticas (pp. 83-101). São Paulo: Sumus.

Sales, L. M. de M. (2003). Justiça e mediação de conflitos. Belo Horizonte: Del Rey.

Sales, L. M. de M. (2007). Mediação de conflitos: família, escola e comunidade. Florianópolis: Editora Conceito.

Soares, M. N. (2017). Conflitualidade e violência na escola: Um diagnóstico concelhio e a avaliação do impacto de uma proposta de intervenção. [Tese de doutorado, Universidade da Beira Interior].

Six, J. F. (2003). Dinâmica da mediação. Belo Horizonte: Del Rey.

Torrego, J. (2003). Mediação de conflitos em instituições educativas. Porto: Asa.

Vasconcellos, C. S. (2009). Indisciplina e disciplina escolar: Fundamentos para o trabalho docente. São Paulo: Cortez. 
Vol. 7 | Investigação Qualitativa em Educação: Avanços e Desafios

Vygotski, L. S. (1925-1991). Obras Escogidas Tomo I (La consciencia como problema de la psicología del comportamiento). Madrid: Aprendizaje Visor y Ministerio de Educación y Ciencia.

Vygotski, L. S. (1931/1995). Obras Escogidas Tomo III (Historia del Desarrollo de las Funciones Psíquicas Superiores). Madrid: Visor.

Vygotski, L. S. (1934-1982). Obras Escogidas Tomo II (Pensamiento Y Lenguaje). Moscú: Editorial Pedagógica Press. 